\title{
Estudio comparativo de la eficacia quirúrgica en la prostatectomía abierta y laparoscópica: reconstrucción virtual de la próstata y cuantificación del tejido periprostático
}

\author{
Diaz JI, Corica A, McKenzie R, Schellhammer PF*. \\ Servicios de Urología y Anatomía Patológica y Virginia Prostate Center, Eastern Virginia Medical School, \\ *Dept of Electronic and Computer Modeling. Old Dominion University, Norfolk, VA
}

Actas Urol Esp. 2007;31(9):1045-1055

\section{RESUMEN}

ESTUDIO COMPARATIVO DE LA EFICACIA QUIRÚRGICA EN LA PROSTATECTOMIA ABIERTA Y LAPAROSCÓPICA: RECONSTRUCCIÓN VIRTUAL DE LA PRÓSTATA Y CUANTIFICACIÓN DEL TEJIDO PERIPROSTÁTICO

Introducción: La introducción de la cirugia laparoscópica como medio de realizar la prostatectomía radical precisa de un método objetivo para evaluar la idoneidad de este nuevo procedimiento quirúrgico. Los parámetros tradicionales, incluidos la incidencia de márgenes quirúrgicos positivos, son útiles, pero no suficientemente objetivos. Diferentes autores publican distintos criterios para definir los márgenes quirúrgicos positivos. Además, existen algunos artefactos técnicos que pueden ocurrir durante el procesamiento de la pieza quirúrgica por el patólogo, los cuales pueden dar lugar a márgenes falsamente positivos. Hemos usado un programa de modelización por ordenador acoplado al escaneado de las imágenes seriadas de cortes histológicos de la glándula completa, con el fin de determinar el porcentaje del tejido extracapsular que rodea a las glándulas prostáticas, tanto las extirpadas mediante la técnica abierta retropúbica como las extirpadas mediante laparoscopia. Este porcentaje puede considerarse un parámetro objetivo que potencialmente pueda predecir el beneficio de la cirugía en cuanto al control del cáncer, así como el éxito clínico del procedimiento quirúrgico. La correlación con los resultados clínicos a largo plazo, - supervivencia y recidiva bioquímica -servirán para validar en última instancia la utilidad clínica de este parámetro en años venideros.

Materiales y métodos: Para este estudio se dispuso de un total de 32 piezas quirúrgicas de la próstata, incluidas 15 piezas de próstata de pacientes sometidos a prostatectomía radical abierta y 17 piezas de próstata de pacientes sometidos a prostatectomía laparoscópica. Después de la cirugía y de 24 horas de fijación en formol, se tomaron cortes seriados para realizar secciones completas ("whole mount") de la próstata a intervalos de 5 mm de grosor. Un patólogo experto en uropatología revisó las secciones completas y dibujó los contornos de la cápsula prostática y del tumor en cada corte tisular. Las imágenes seriadas de la glándula completa y del tejido peri o extraprostático circundante se escanearon para producir imágenes digitales, utilizándose un programa informático para crear un archivo con información sobre la cápsula y un archivo con información sobre el tejido fibroadiposo circundante (extraprostático). Estos procedimientos permitieron la reconstrucción de un modelo tisular tridimensional de la cápsula prostática y del tejido extraprostático circundante. Se generaron dos archivos de nubes de puntos por separado, con la intención de representar modelos tanto de la cápsula como del tejido extraprostático y se usaron algoritmos de software para generar diferencias en las nubes de puntos y, de este modo, cuantificar la magnitud de la cobertura del tejido extracapsular, un parámetro que consideramos indicativo de la idoneidad de la técnica quirúrgica.

Resultados: El porcentaje global de superficie de la glándula prostática cubierto por tejido fibroadiposo extracapsular fue estadisticamente mayor en las piezas extirpadas mediante la técnica laparoscópica, en comparación con la técnica retropúbica. Cuando se evaluó un análisis segmentario del porcentaje de cobertura de la glándula, se encontró que el porcentaje era significativamente mayor en los segmentos apical e inferolateral de las glándulas extirpadas sin preservación de los nervios y en el segmento apical de las glándulas extirpadas con preservación de los nervios para la prostatectomía laparoscópica.

Conclusiones: En nuestra serie, la prostatectomía laparoscópica aportó una cobertura tisular extracapsular superior a la prostatectomía retropúbica. Del mismo modo, la prostatectomía laparoscópica aportó una cobertura tisular superior en las regiones inferolateral y apical de las glándulas extirpadas sin preservación de los nervios y en la región apical de las glándulas extirpadas con preservación de los nervios. Así pues, la idoneidad quirúrgica de esta técnica, en comparación con el procedimiento retropúbico, parece ser superior.

Palabras clave: Prostatectomía laparoscópica. Prostatectomía retropúbica. Cobertura extracapsular. Seccionamiento completo. Reconstrucción en 3D.
\end{abstract}

\section{ABSTRACT}

COMPARATIVE STUDY OF SURGICAL EFFICACY IN OPEN VERSUS LAPAROSCOPIC PROSTATECTOMY: VIRTUAL PROSTATE RECONSTRUCTION AND PERIPROSTATIC TISSUE QUANTIFICATION

Introduction: The introduction of laparoscopic surgery as a procedure to perform radical prostatectomy needs an objective method to evaluate the suitability of this new surgical procedure. The traditional parameters, including the incidence of positive surgical margins, are useful, but not sufficiently objective. Different authors publish different criteria to define positive surgical margins. In addition, there are some technical problems that may ocur during the processing of the surgical specimen by the pathologist, which can give false positive margins. We have used a computer modeling software in connection to scanned images from serial sections of the whole gland, to determine the percentage of extracapsular tissue that surrounds the prostate glands, removed by both, open retropubic and laparoscopic procedures. This percentage can be considered as an objective parameter which can potentially predict the benefit of surgery in predicting cancer control, as well as the clinical success of the surgical procedure. The correlation with the clinical results in the long term, - survival and biochemical recurrence - will be useful to validate as a last resort the clinical utility of this parameter in the coming years.

Materials and Methods: We had a total of 32 prostate surgical specimens, 15 from patients who underwent open retropubic prostatectomy and 17 from patients who underwent laparoscopic prostatectomy for this study. After surgery and 24 hours formol fixation, serial cuts were taken at 5 mm thickness intervals to make complete sections ("whole mount") of the prostate. An expert uropathologist reviewed all the surgical sections and drew in each tissue cut the prostatic capsule and tumor contours. The serial images of the whole gland and surrounding prostate tissue were scanned to produce digital images, using a computer software to create a file with capsule information and a file with information on the surrounding fibroadipose tissue (extraprostatic). These procedures allowed the reconstruction of a threedimensional tissue model of the prostatic capsule and the surrounding extraprostatic tissue. Two separate point clouds files were generated, with the purpose of representing capsule and extraprostatic tissue models and software algorithms were used to generate differences in point clouds and thereby quantifying the extracapsular tissue coverage dimension, a parameter that we considered indicative of the adequeacy and feasibility of the surgical procedure.

Results: The global percentage of prostate gland surface covered by extracapsular fibroadipose tissue was statistically higher in specimens removed by a laparoscopic procedure when compared to the open retropubic procedure. When a segmental analysis of the gland percentage of coverage was evaluated, it was found this percentage was significantly higher in the apical and inferolateral segments of those glands removed without nerves preservation and in the apical segments of those glands removed with nerves preservation for the laparoscopic prostatectomy.

Conclusions: In our series, laparoscopic prostatectomy contributed superior extracapsular tissue coverage than retropubic prostatectomy. Similarly laparoscopic prostatectomy produced a superior tissue coverage in inferolateral and apical regions on those glands removed without nerve preservation and in the apical regions of those glands removed with nerve preservation. Therefore, the surgical suitability of this technique, when compared to the retropubic, seems to be higher.

Keywords: Laparoscopic prostatectomy. Retropubic prostatectomy. Extracapsular extension. Whole Mount. 3D reconstruction. 
$\mathrm{L}^{2}$ a primera gran serie de prostatectomía laparoscópica fue comunicada en el Montsouris Hospital Center por el grupo de Vallancian y Guillonneau $^{1}$. Su éxito con esta técnica coincidió con una mayor demanda de tratamientos mínimamente invasivos por parte de los pacientes, lo que rápidamente impulsó a la prostatectomía laparoscópica como la corriente dominante en la cirugía del cáncer de próstata. A objeto de investigar si esta técnica proporciona un control adecuado del cáncer y si su morbilidad es menor, este nuevo planteamiento quirúrgico debe compararse con la cirugía estándar, la prostatectomía abierta. La morbilidad puede valorarse a intervalos periódicos durante los primeros 6-24 meses postoperatorios. Sin embargo, la historia natural del carcinoma de próstata, que se caracteriza por recidivas bioquímicas y/o clínicas muy diferidas, precisaría muchos años de seguimiento antes de que pudieran realizarse afirmaciones definitivas sobre el control del cáncer.

Determinados parámetros anatomopatológicos, concretamente la incidencia de márgenes positivos, pueden valorarse inmediatamente para ayudar a determinar la idoneidad de un procedimiento quirúrgico en lo que se refiere a conseguir la extirpación completa de la glándula prostática y del tumor. Sin embargo, el estado de los márgenes quirúrgicos puede depender mucho de varios factores subjetivos, como la forma en que se procesa y examina la pieza quirúrgica y de como y con que criterios define el patólogo el margen tumoral positivo. De hecho, existen grandes diferencias en las definiciones aportadas en la bibliografía por distintos autores. En último término, depende también de la biología de cada tumor individualizado. Además es importante destacar que la valoración rutinaria de los márgenes quirúrgicos a menudo no incluye la identificación de las áreas donde las glándulas benignas se extienden hasta el margen quirúrgico, lo que nosotros definimos como "márgenes parenquimatosos positivos". En esta situación, sólo la buena suerte reduce la importancia de este hallazgo, ya que el cáncer, de forma casual, no se encuentra en el área del margen quirúrgico de una técnica que por lo demás ha resultado adecuada. En este sentido, hemos comunicado nuestra experiencia con estos dos abordajes quirúrgicos en la Eastern Virginia Medical School ${ }^{2,3}$.
La evaluación de las piezas quirúrgicas en la prostatectomía, usando parámetros más estandarizados y objetivos, sería de gran utilidad a la hora de determinar los méritos relativos de los diferentes abordajes quirúrgicos para realizar una prostatectomía radical. En el presente estudio hemos diseñado una valoración más completa y cuidadosa de la idoneidad de estos dos procedimientos quirúrgicos, mediante modelización por ordenador de los cortes histológicos seriados de la próstata en su totalidad, después de realizar la extirpación quirúrgica. De este modo, se puede evaluar la cantidad de tejido fibroadiposo periprostático, el cual hemos cuantificado como el porcentaje de superficie glandular cubierto por esta envoltura de tejido fibroadiposo extraprostático, previa reconstrucción virtual tridimensional de las piezas quirúrgicas obtenidas mediante cirugía laparoscópica y retropúbica abierta.

\section{MATERIALES Y MÉTODOS}

\section{Piezas Quirúrgicas}

Las prostatectomías abiertas fueron realizadas por dos cirujanos, cada uno de los cuales había terminado una formación pos-residencia en oncología quirúrgica. Las prostatectomías laparoscópicas fueron realizadas por dos cirujanos con formación pos-residencia en laparoscopia y cuya experiencia incluía más de 50 procedimientos de prostatectomía laparoscópica cada uno.

Las piezas quirúrgicas de la próstata de 15 pacientes sometidos a prostatectomía radical abierta (retropúbica) y de 17 pacientes sometidos a prostatectomía laparoscópica se incluyeron en el estudio, teniendo en cuenta el pertinente consentimiento por escrito del paciente y la aprobación del protocolo por el Comité de Revisión Institucional de la Eastern Virginia Medical School.

\section{Procesamiento tisular "de preparación integra" en patología quirúrgica y evaluación histopatológica:}

Inmediatamente después de la cirugía, las piezas de prostatectomías se midieron craneocaudalmente, anteroposteriormente y transversalmente y también se pesaron. Se describió el aspecto 
macroscópico de la superficie capsular y además, toda la glándula se tiñó en su superficie con tinta azul en el lado derecho y con tinta roja en el lado izquierdo para de este modo marcar los márgenes quirúrgicos. Se marcó también la línea media posterior de la glándula con una raya de tinta negra dirigida en dirección craneocaudal, desde la base hasta el vértice de la glándula. Se fijó la glándula durante 24 horas en formol neutro tamponado al $10 \%$. Después de la fijación, la glándula se cortó transversalmente desde su vértice hasta su base a intervalos de $5 \mathrm{~mm}$ de grosor, según el procedimiento del procesamiento histológico del "seccionamiento completo" o "whole mount" 4 . Este procedimiento es difícil de realizar, no siendo habitual ni rutinario en la mayoría de los Servicios de Anatomía Patológica. Además precisa instrumentación y suministros especiales, los cuales se muestran en la Figura 1a-c. Se tomaron cortes escalonados de $5 \mathrm{~mm}$ de espesor de toda la glándula en un plano perpendicular al eje de la uretra prostática, después de ser esta estirada con una sonda durante su fijación. Para asegurar la precisión en el espesor de los cortes, estos se realizaron con la ayuda de una caja de ingletes graduada a $5 \mathrm{~mm}$ de espesor (Fig. 1a). El primer corte, es decir, el cono apical, se seccionó a su vez seriadamente, desde su cara anterior a la posterior y en un plano perpendicular a la curvatura del vértice de la glándula, para aumentar al máximo la disponibilidad de los márgenes quirúrgicos para su revisión al microscopio. Los perfiles restantes incluían el tejido prostático de la glándula completa así como los tejidos periprostáticos circundantes para cada nivel escalonado de $5 \mathrm{~mm}$ de espesor y siempre desde el vértice hasta la base de la glándula. Usando este procedimiento, sometimos toda la glándula y las vesículas seminales a evaluación histopatológica. Se procesaron los perfiles escalonados de la glándula para efectuar los cortes en parafina a $5 \mu \mathrm{m}$ de espesor y en condiciones estándar. Para ello, se incluyeron en parafina usando casetes grandes de 5 x 7,5 cm (Fig. 1b). Estos grandes bloques de parafina se cortaron con un microtomo especial de deslizamiento (Fig. 1c) para generar cortes tisulares de toda la glándula y para cada perfil escalonado a intervalos de $5 \mathrm{~mm}$. Después, se tiñeron posteriormente con hematoxilina-eosina
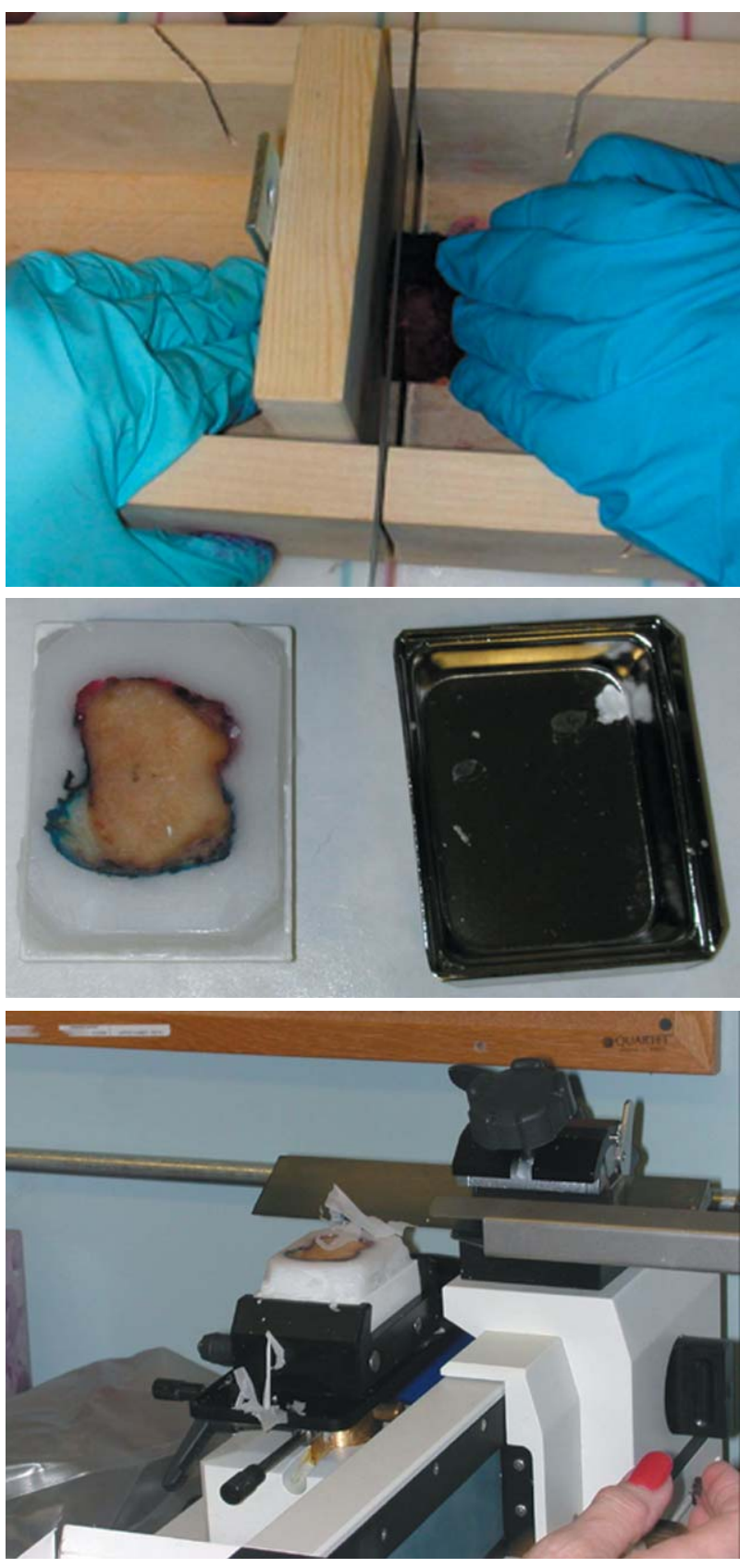

FIGURA 1. Algunos de los instrumentos y suministros más criticos empleados para el procesamiento de "seccionamiento completo" de la próstata: (A) una caja de ingletes para cortes precisos a intervalos de $5 \mathrm{~mm}$, (B) inclusión en un supercassette de $5 \times 7,5 \mathrm{~cm}$, (C) Microtomo de deslizamiento para cortes tisulares de gran dimensión.

y se montaron en portaobjetos grandes. Un uropatólogo evaluó cuidadosamente los cortes tisulares de cada pieza para valorar todos los parámetros diagnósticos y pronósticos considerados estándar, esto es, los que recomienda la lista de comprobación del Colegio de Patólogos de Estados Unidos 
para las piezas de prostatectomía y, de este modo, garantizar una evaluación adecuada de todos los parámetros pronósticos importantes en el informe de patología quirúrgica. Además, el patólogo realizó un cuidadoso mapeo microscópico de los contornos de la cápsula prostática en cada corte tisular usando un rotulador negro. También marcó los contornos periféricos del tumor con un rotulador azul. En las Figuras 2a, $2 \mathrm{~b}$ y $2 \mathrm{c}$ se muestra un ejemplo de preparaciones tisulares "completas" de tres cortes escalonados seriados a intervalos de $5 \mathrm{~mm}$ de grosor de una pieza de próstata. Asimismo, en la Figura 3, también se muestra un ejemplo del informe de patología quirúrgica procesada mediante el método histológico del "seccionamiento completo". De otra parte, si la cápsula prostática no era microscópicamente identificable en una región concreta, se marcaba un contorno discontinuo dibujando la cápsula en aquellas regiones donde se identificaba fácilmente, luego se reconstruía la circunferencia completa uniendo las líneas discontinuas al mejor ajuste para la forma natural de la glándula prostática. Si se realiza una incisión en la cápsula prostática durante el procedimiento quirúrgico, (como se ponía de manifiesto cuando se identificaban glándulas benignas extendiéndose al margen quirúrgico, marcado con tinta, se indicaba esta región con una flecha verde (Fig. 4a). Si el tumor penetraba la cápsula prostática, se marcaba esta región con una flecha azul; pero además, si el tumor se extendía al margen quirúrgico (marcado con tinta), se indicaba el área con una flecha roja. Se muestra un ejemplo de penetración capsular del tumor con extensión al margen de resección quirúrgica marcado con tinta (Fig. 4b).

Se procedió a escanear con alta resolución el conjunto completo de las preparaciones histológicas conteniendo la totalidad de la glándula de los diferentes cortes escalonados a intervalos de 5 $\mathrm{mm}$, para el posterior análisis de las imágenes en ordenador y su reconstrucción tridimensional (3D). La raya negra que marcaba la linea media de la glándula fue empleada posteriormente por los técnicos de informática para alinear en su posición correcta cada corte independiente proveniente de cada nivel escalonado o intervalos cada $5 \mathrm{~mm}$ de grosor y proceder así a la reconstrucción

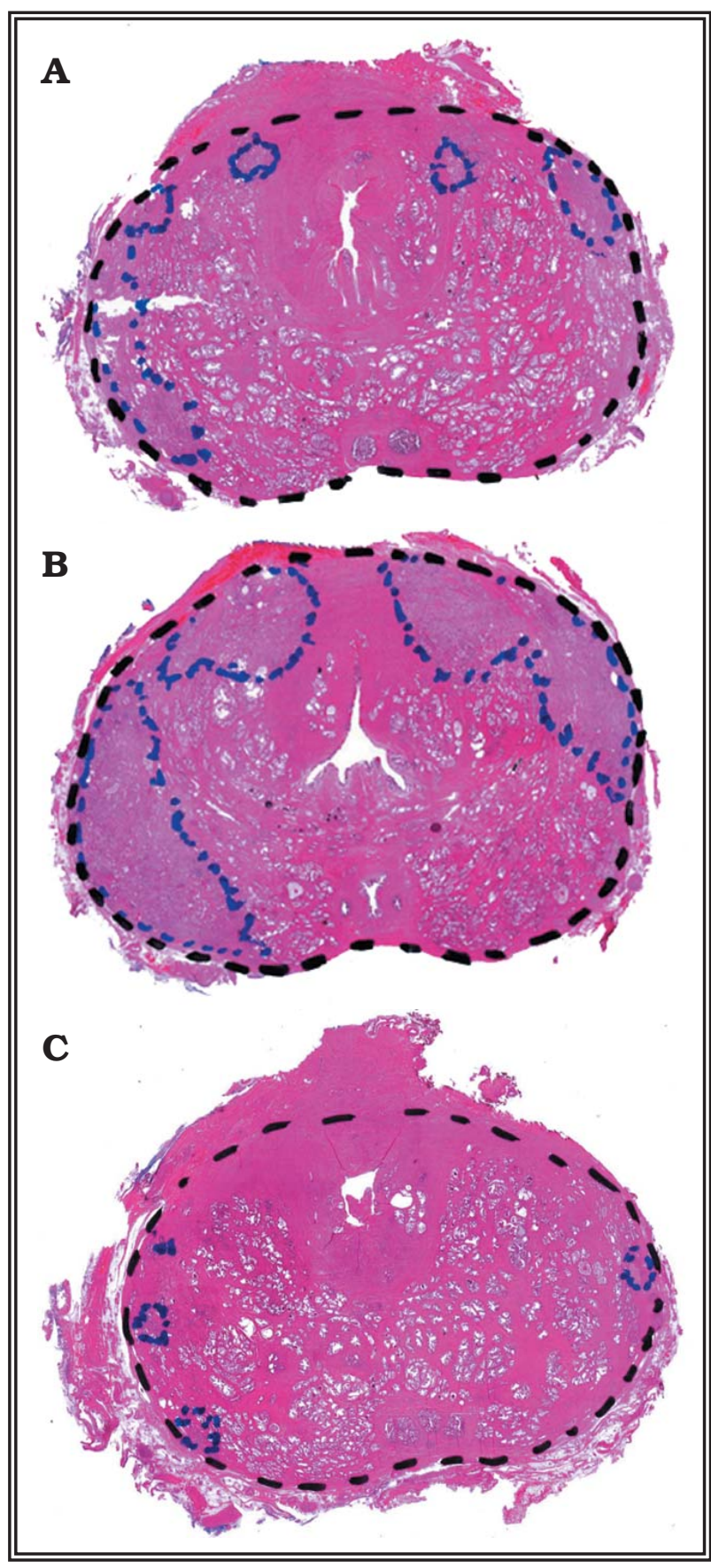

FIGURA 2. Cortes tisulares seriados de una próstata en: (A) el nivel de $25 \mathrm{~mm}$, (B) el nivel de $30 \mathrm{~mm}$, (C) el nivel de $35 \mathrm{~mm}$. La linea negra discontinua representa el contorno de la cápsula prostática y la línea discontinua azul representa los contornos periféricos de los tumores. El tejido fuera de la linea negra es el tejido fibroadiposo peri o extraprostático, que en este caso es más abundante en el nivel de $35 \mathrm{~mm}$.

tridimensional (3D) de la glándula completa (reconstrucción virtual). La reconstrucción 3D final de la glándula se basó en todos los cortes escalonados de los niveles de $5 \mathrm{~mm}$, desde el vér- 


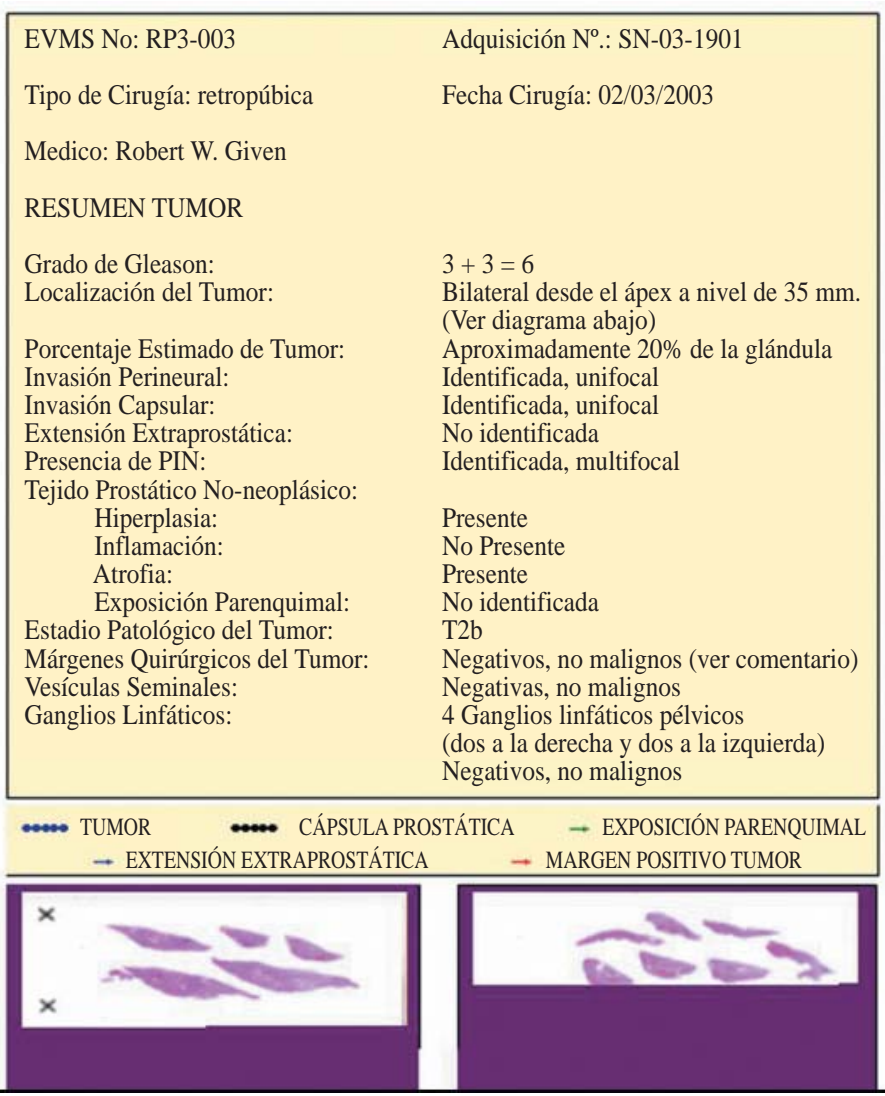

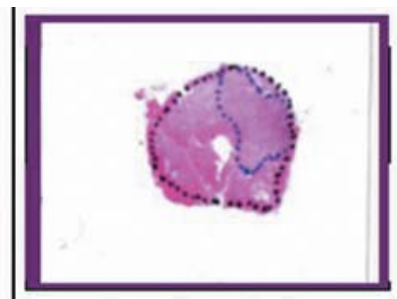

Perfil de Tejido a $5 \mathrm{~mm}$

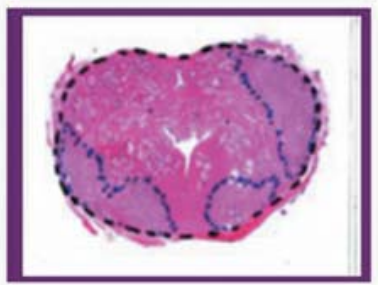

Perfil de Tejido a $25 \mathrm{~mm}$

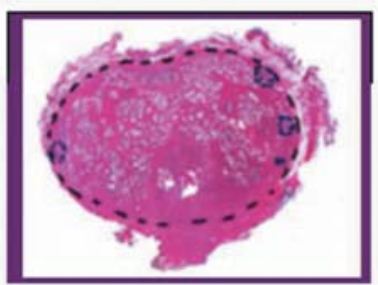

Perfil de Tejido a $35 \mathrm{~mm}$

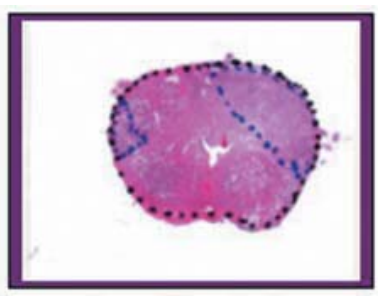

Perfil de Tejido a $10 \mathrm{~mm}$

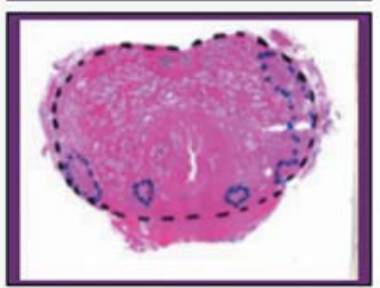

Perfil de Tejido a $30 \mathrm{~mm}$

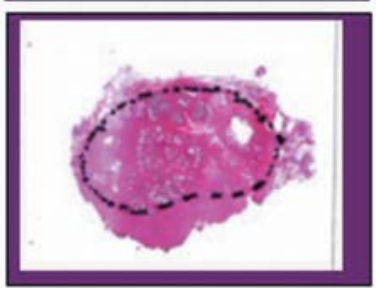

Perfil de Tejido a $40 \mathrm{~mm}$

FIGURA 3. Ejemplo de un informe de Anatomía Patológica de una prostatectomía procesada mediante "seccionamiento completo" tal como se efectúa en la Eastern Virginia Medical School. El informe escrito a la izquierda se complementa con imágenes escaneadas de los cortes tisulares de "secciones completas" de los múltiples niveles escalonados a intervalos $5 \mathrm{~mm}$ de grosor (los fragmentos del cono apical se muestran por separado).

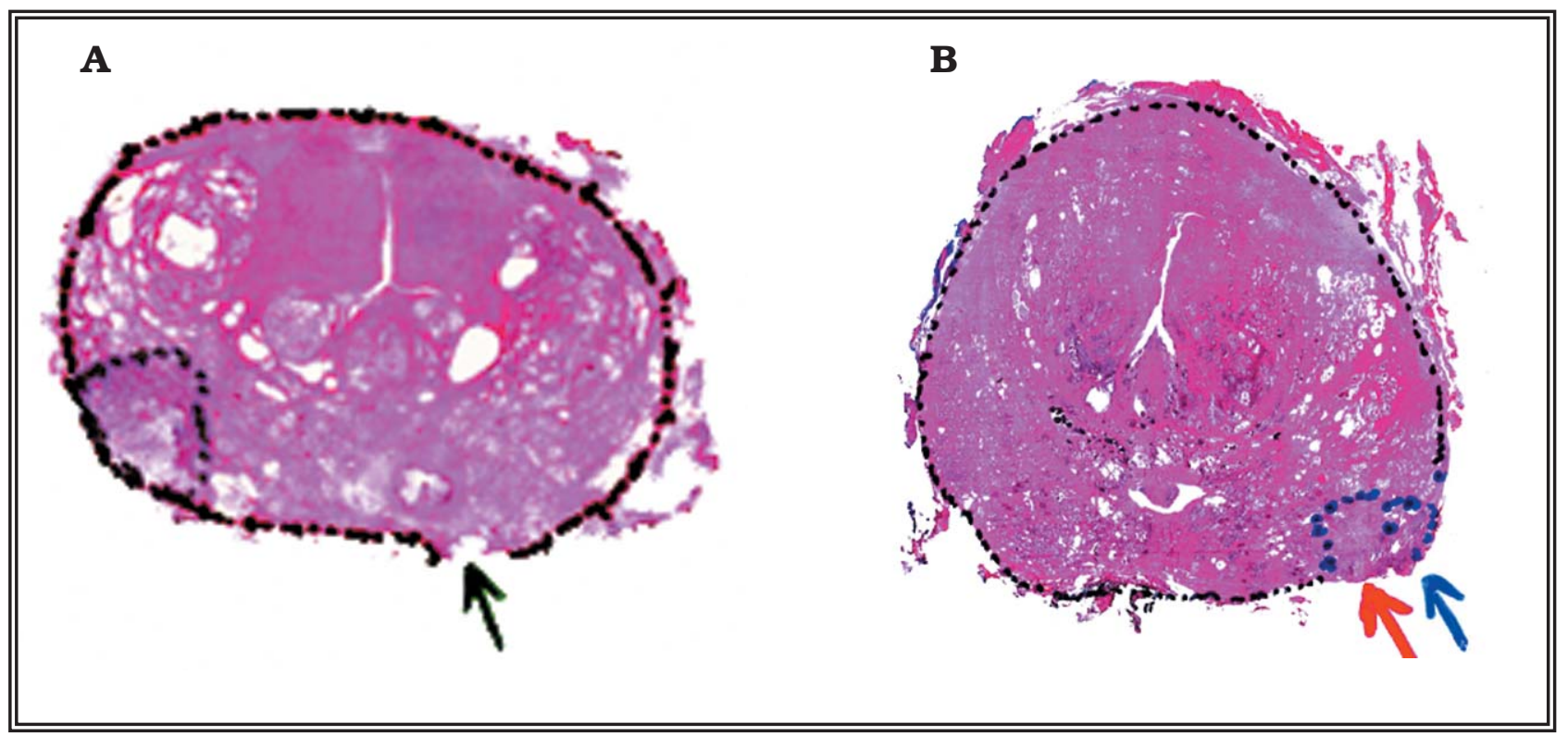

FIGURA 4. Ejemplo de cortes tisulares de "secciones completas" con márgenes positivos: (A) margen positivo de parénquima benigno, (B) penetración tumoral extracapsular con márgenes tumorales positivos. 
tice a la base, exceptuando el cono apical inicial (primer perfil de $5 \mathrm{~mm}$ de grosor). Para poder efectuar una revisión anatomopatológica adecuada de esta región de la pieza quirúrgica - estándares recomendados por el Colegio de Patólogos de Estados Unidos-, hubo que cortar seriadamente de adelante atrás el cono apical, para aumentar al máximo la representación de los márgenes quirúrgicos del cono apical durante la evaluación microscópica, lo que condujo a una fragmentación excesiva del cono apical, haciendo inalcanzable la reconstrucción 3D a este nivel. No obstante, la revisión microscópica reveló que la gran mayoría de las piezas quirúrgicas no contenían o era muy escaso el tejido extracapsular rodeando los primeros $5 \mathrm{~mm}$ del cono apical. En general, el tejido periprostático extracapsular circundante comenzó a apreciarse mejor, cuando se pasaba a los niveles escalonados de 5 a $10 \mathrm{~mm}$ desde el cono apical y fue fundamentalmente abundante en la región media de la glándula. Por tanto, la no inclusión de esta región de la glándula en la reconstrucción 3D no supuso una pérdida significativa de información. Según la descripción de la hoja quirúrgica, las piezas se identificaron como si se hubieran realizado sin preservación de nervios, con preservación unilateral de nervios o con preservación bilateral de nervios. Se consideró que el margen quirúrgico era positivo para el tumor, cuando alguna glándula tumoral o células tumorales se extendían y tocaban la superficie de extirpación de la glándula, la cual fue reconocida por la presencia de tinta (margen quirúrgico), siempre y cuando el patólogo no reconociera artefactos de disrupción del tejido circundante en el área afectada, el cual se aprecia mejor a bajo aumento (4X). Utilizando los mismos criterios, se consideró que un margen era positivo para parénquima benigno, si había glándulas benignas extendiéndose hasta la resección del margen marcado con tinta; así mismo, siempre y cuando el patólogo no reconociese un artefacto obvio de disrupción de tejido que hubiera facilitado la penetración de la tinta dentro del tejido, sin ser este representativo del margen. Este estudio no incluye una serie consecutiva de pacientes porque el procesamiento mediante "seccionamiento completo" no es un procedimiento habitual o rutinario en nuestro
Servicio de Anatomía Patológica. El uropatólogo de nuestro centro accedió a participar en este proyecto y evaluó todos los casos como ya hemos descrito. Por tanto, el cirujano no sabía si su caso entraría en este protocolo de investigación específico a la hora de efectuar la cirugía o de enviar la pieza quirúrgica a Anatomía Patológica. Esto sirvió para omitir el riesgo de selección por parte del cirujano.

\section{Escaneado y reconstrucción 3D por ordenador}

Los cortes de tejido de secciones completas de la glándula fueron escaneados a alta resolución (1.200 dpi) para ser convertidos en imágenes digitales. El archivo de imagen de cada corte fue manipulado para crear otros 2 archivos; uno que contenía la información sobre la cápsula y otro que contenía la información sobre el tejido fibroadiposo peri o extraprostático. Se identificó la cobertura tisular y el estado de los márgenes, teniendo en cuenta el lado de la glándula (derecha frente a izquierda según el color de la tinta). Como este estudio está orientado a la técnica, era importante identificar el estado del margen y el tejido según el lado, así como según la pieza, es decir, 64 lados para 32 piezas.

Se empleó un software de modelización en 3D desarrollado internamente (Departamento de Informática de Universidad de Old Dominon, Norfolk, Virginia) para extraer las curvas geométricas. La serie de curvas obtenida de las imágenes digitales de todos los cortes (Fig. 5) se
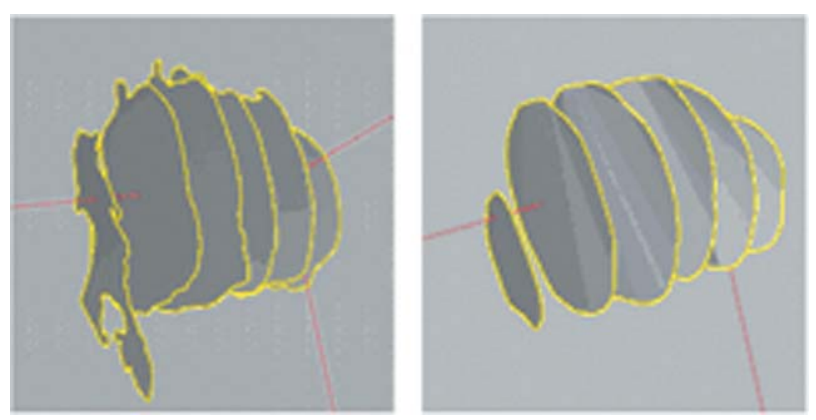

FIGURA 5. Serie de curvas amarillas obtenidas de todas las imágenes seriadas escalonadas a intervalos de $5 \mathrm{~mm}$ que muestran un modelo de cápsula discontinua (imagen de la izquierda) y un modelo de tejido extraprostático discontinuo (imagen derecha). Las lineas rojas representan un sistema de ejes de coordenadas empleado para el alineamiento de los perfiles. 
integraron; para ello, se colocaron una encima de otra para reconstruir un modelo de la cápsula y otro modelo de tejido extraprostático (Fig. 6). Después de reconstruir las mallas, se generó una nube de puntos limitada por las mallas reconstruidas para los modelos capsular y extracapsular.. Se muestra un ejemplo de nube de puntos (Fig. 7). Los algoritmos de software usaron las diferencias de las nubes de puntos para cuantificar la medida de cobertura del tejido extracapsular. La reconstrucción prostática se dividió geográficamente en segmentos para permitir realizar cálculos separados de la cobertura del tejido extracapsular específicamente en los segmentos inferolateral y apical de la próstata (Fig. 8).
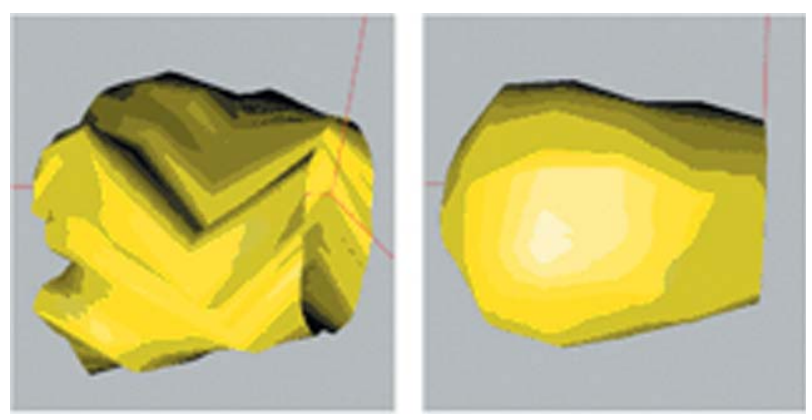

FIGURA 6. Las curvas amarillas que se muestran en la figura 6 se integran y se colocan una encima de otra para reconstruir un modelo continuo de cápsula (imagen de la izquierda) y un modelo continuo de tejido extraprostático (imagen de la derecha) usando el mismo sistema de ejes de coordenadas (lineas rojas) con fines de alineamiento. El extremo recto y truncado de la glándula en su lado derecho de la figura es debido a la ausencia al cono apical que no se incluyó en la reconstrucción $3 D$.

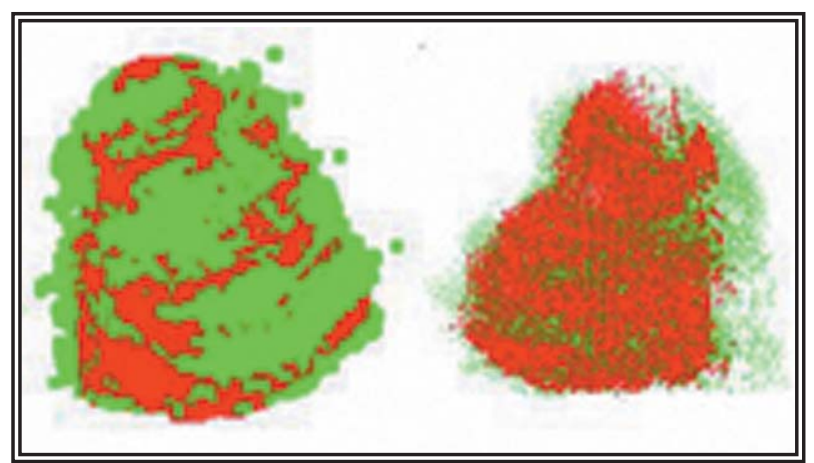

FIGURA 7. Después de reconstruir las mallas como se muestra en la figura 6, se generó una nube de puntos limitada por las mallas reconstruidas para los modelos de la cápsula de la glándula y extracapsular. Se muestran dos vistas de la matriz de nube de puntos en $3 D$ visualizada con puntos rojos que representan la glándula y puntos verdes que representan el tejido fibroadiposo circundante.

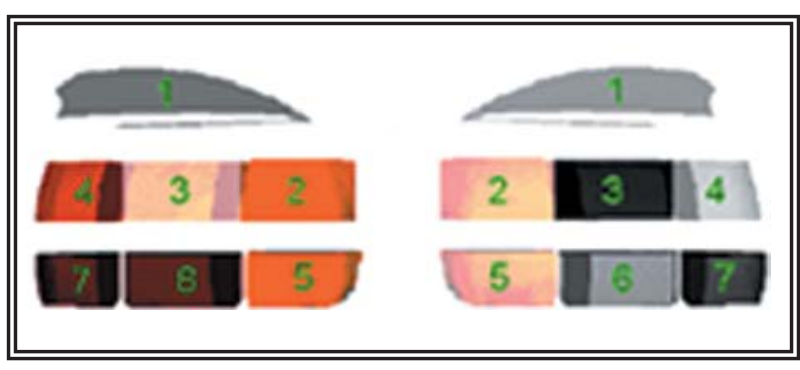

FIGURA 8. La reconstrucción prostática se dividió geográficamente en segmentos para poder realizar cálculos separados de la cobertura por tejido extracapsular especificamente en los segmentos inferolateral $(5,6,7)$ y apical $(2,5)$ de la próstata.

Luego se analizaron las nubes de puntos superponiendo la nube de puntos de tejido extraprostático sobre la nube de puntos de la glándula (tejido dentro del contorno capsular) y determinando qué áreas quedaban desnudas. Este proceso comenzaba atravesando la nube de puntos resultante hasta que se encontraba un punto en la superficie de la cápsula. Posteriormente, se realizaba una comprobación de vecindad de puntos de tejido extraprostático. Los puntos tisulares extraprostáticos encontrados de esta manera aumentaban el recuento de puntos de la glándula cubiertos, mientras contribuían también al número total de puntos de la glándula encontrados (cubiertos o no cubiertos). La proporción de estos recuentos aportó el porcentaje de cobertura de tejido fibroadiposo pericapsular para cada próstata en particular. Se realizó una comprobación de vecindad de 8 (vecindad de Moore) para los puntos de la glándula, así como una comprobación de vecindad de 4 (Von Neumann) para los puntos de tejido extraprostático. Estas comprobaciones se realizaron desde el corte de la base de la próstata hasta el corte final en la región apical.

Se usó la prueba estadística de la t independiente para comparar los dos tipos de muestras y generar la hipótesis de que un grupo tenía un mayor porcentaje medio de cobertura periprostática que el otro. Esta hipótesis es unilateral y por tanto, usamos el valor de $\mathrm{p}$ unilateral para determinar si las medias más altas observadas eran significativas, teniendo en cuenta que un valor de p menor de 0,05 indica significación.

\section{RESULTADOS}

De los 15 pacientes sometidos a prostatectomía radical abierta, en 4 se realizaron procedi- 
mientos sin preservación de nervios, en 2 pacientes se hizo preservación unilateral de nervios y en 9 pacientes se hizo preservación bilateral de los nervios. Por tanto, hubo 20 lados con preservación de nervios y 10 sin preservación de nervios.

De los 17 pacientes sometidos a prostatectomía radical laparoscópica, en 6 se realizaron procedimientos sin preservación de los nervios, en 3 pacientes se hizo preservación unilateral de los nervios y en 8 pacientes se hizo preservación bilateral de los nervios. Por tanto, hubo 19 lados con preservación de nervios y 15 sin preservación de nervios.

Cuando se compararon los lados obtenidos mediante cirugia abierta y los obtenidos por laparoscópia, según la cirugia de preservación o no preservación de nervios, hubo un mayor porcentaje de cobertura de la superficie capsular por tejido extracapsular asociado a las piezas laparoscópicas, el cual fue estadísticamente significativo (Tabla 1). Por tanto, la extirpación quirúrgica laparoscópica de la próstata parece ser más adecuada que la extirpación abierta (retropúbica) a juzgar por el hecho de que el procedimiento laparoscópico aportó un mayor porcentaje de cobertura de la envoltura periprostática extracapsular.

Se prestó atención específica a los segmentos apical e inferolateral (numerados como 2,5; y 5, 6, 7 de la Fig. 8) de los lados sometidos a disección sin preservación de los nervios, de los cua- les hubo 15 para el abordaje laparoscópico y 10 para el abordaje abierto. Se observó que las piezas laparoscópicas tenían un porcentaje estadísticamente mayor de cobertura del segmento inferolateral (5,6,7 de la Figura 8) y también del segmento apical (2,5 en la Figura 8), excluyendo de este último el cono (primeros $5 \mathrm{~mm}$ del vértice del apex). Como topográficamente esta región de la glándula registra la mayor incidencia de márgenes quirúrgicos positivos en las series de prostatectomía, el protocolo estándar de sumisión de tejido en las prostatectomías establece la necesidad de efectuar cortes adicionales para multiplicar la exposición de los márgenes quirúrgicos durante la evaluación microscópica, lo cual resulta en una fragmentación excesiva que imposibilita el análisis y su reconstrucción por ordenador (Tabla 2).

En los lados sometidos a disección con preservación de nervios, de los cuales hubo 19 con el abordaje laparoscópico y 20 con el abordaje abierto, se observó un porcentaje significativamente mayor de cobertura en el segmento apical de los lados disecados mediante laparoscopia (Tabla 3). La incidencia de márgenes positivos por lado para las glándulas, tanto benignas como malignas, para los abordajes con y sin preservación de nervios en cirugía abierta y laparoscópica se indica en la Tabla 4. Estos márgenes eran apicales en 2 y posterolaterales en otros 2 (uno, pT3)

Tabla 1. Porcentaje de superficie glandular cubierta por tejido fibroadiposo extracapsular distribuido por lados con preservación de nervios y sin ella

\begin{tabular}{|c|c|c|c|c|c|}
\hline \multirow[t]{2}{*}{ Abordaje quirúrgico } & \multicolumn{2}{|c|}{ Retropúbico (abierto) } & \multicolumn{3}{|c|}{ Laparoscópico } \\
\hline & Media & Desv. estándar & Media & Desv. estándar & $\mathbf{p}$ \\
\hline Preservación de nervios & $72,8 \%$ & 11,1 & $78,3 \%$ & 7,3 & 0,038 \\
\hline Sin preservación de nervios & $70,6 \%$ & 7,4 & $80,3 \%$ & 9,8 & 0,007 \\
\hline
\end{tabular}

Tabla 2. Porcentaje de la superficie glandular cubierto por tejido fibroadiposo extracapsular por segmento inferolateral o apical

\section{Lados sin preservación de nervios}

\begin{tabular}{|c|c|c|c|c|c|c|}
\hline \multicolumn{3}{|c|}{ Segmento inferolateral $5,6,7$ (Fig. 5) } & & \multicolumn{2}{|c|}{ Segmento apical 2,5 (Fig. 5) } & \\
\hline $\begin{array}{l}\text { Abordaje quirúrgico } \\
\text { (no lados) }\end{array}$ & Media & $\begin{array}{l}\text { Desviación } \\
\text { estándar }\end{array}$ & & Media & $\begin{array}{l}\text { Desviación } \\
\text { estándar }\end{array}$ & \\
\hline Retropúbico (10) & $69,43 \%$ & 15,35 & $\mathrm{p}=0,049$ & $68,53 \%$ & 13,87 & $\mathrm{p}=0,042$ \\
\hline Laparoscópico (15) & $79,76 \%$ & 14,32 & & $79,71 \%$ & 15,96 & \\
\hline
\end{tabular}


Tabla 3. Porcentaje de superficie glandular cubierta por tejido fibroadiposo extracapsular por segmento apical

\begin{tabular}{lccc}
\hline \multicolumn{4}{c}{ Lados con conservación de nervios } \\
\hline \multicolumn{4}{c}{ Segmento apical 2,5 (Fig 5) } \\
\cline { 2 - 4 } $\begin{array}{l}\text { Abordaje quirúrgico } \\
\text { (n.o lados) }\end{array}$ & Media & St. Deviation & \\
\hline Retropúbico (20) & $64,8 \%$ & 20,02 & $\mathrm{p}=0,007$ \\
Laparoscópico (19) & $78,78 \%$ & 13,50 & \\
\hline
\end{tabular}

y se observaron tanto glándulas benignas como malignas en el área de márgenes positivos. La Tabla 5 enumera los valores de PSA sérico, los casos con un baremo de Gleason desfavorable ( $\geq$ 7), y los volúmenes del tumor y la glándula en los dos tipos de piezas quirúrgicas.

\section{DISCUSION}

La rápida evolución de los abordajes y la tecnología para el tratamiento quirúrgico del cáncer de próstata contrasta con la historia natural prolongada de esta enfermedad, que precisa años e incluso décadas de seguimiento para estudiar adecuadamente la eficacia y los beneficios relativos de

Tabla 4. Resumen de márgenes positivos (por lado)

\begin{tabular}{|c|c|c|}
\hline & Cáncer & Glándula benigna \\
\hline \multicolumn{3}{|l|}{ Abierto $\quad$ (30 lados) } \\
\hline Sin preservación de nervios & $0 / 10$ & $0 / 10$ \\
\hline Con preservación de nervios & $0 / 20$ & $0 / 20$ \\
\hline \multicolumn{3}{|l|}{ Laparoscópico（34 lados) } \\
\hline Sin preservación de nervios & $4 / 15 \dagger \ddagger^{*}$ & $4 / 15 \dagger *$ \\
\hline Con preservación de nervios & $1 / 19+*$ & $1 / 19 \dagger *$ \\
\hline \multicolumn{3}{|c|}{$\begin{array}{l}* \text { - se encontraron tanto glándula benigna como tumor juntos } \\
\dagger-\text { margen positivo en el vértice } \\
\ddagger-\text { pieza pT3 }\end{array}$} \\
\hline & & \\
\hline & Laparoscópico & Abierto \\
\hline $\begin{array}{l}\text { Puntuación desfavorable de Gleason } \\
\text { (n.o de casos con patrón } 4 \text { y puntuación } \\
\text { Gleason } \geq 7 \text { ) }\end{array}$ & $5 / 17$ & $3 / 15$ \\
\hline PSA (med rango) & $5,6(2,4-18,3)$ & $5,6(1,7-15,5)$ \\
\hline Volumen tumoral (med rango) & $4,28(1,33-27,54)$ & $3,01(0,65-11,62)$ \\
\hline Volumen de la glándula (med rango) & $39,7(24-119,8)$ & $59(47-68)$ \\
\hline
\end{tabular}

una modalidad de tratamiento frente a otro. La introducción de un nuevo abordaje quirúrgico presenta siempre el dilema real y práctico de establecer comparaciones inmediatas válidas. Aunque se dispone de diversos parámetros métricos, todos se asocian con ciertas deficiencias. Los criterios para valorar la evolución del cáncer son muy distintos y a menudo, se determinan biológicamente. Aunque la recidiva bioquímica inevitablemente precede a la recidiva clínica, puede producirse muchos años después del tratamiento y no distingue claramente entre recidiva local o distante.

El control local de la enfermedad es una medida fundamental del tratamiento local. Los criterios de valoración de calidad de vida, aunque actualmente se miden de forma más precisa usando instrumentos validados, a menudo están condicionados por las expectativas y las actitudes individuales. La histopatología está sesgada por la experiencia del patólogo, y también por las definiciones empleadas y por los métodos de preparación de la pieza. Las complicaciones peroperatorias (pérdida de sangre, infección, lesión rectal) no reflejan el estado de la pieza extirpada y cuando se emplean abordajes quirúrgicos muy diferentes, puede no tener ninguna relación con la pieza de biopsia; por ejemplo, la pérdida de sangre siempre será menor con la prostatectomía laparoscópica que con la prostatectomía abierta.

La definición del éxito quirúrgico dentro de los límites de una definición anatómica es la escisión completa y total del objetivo quirúrgico, preferiblemente con cierto margen extra para aportar una zona de seguridad y un control eficaz del cáncer mediante la escisión completa del tumor. Podría ser de gran valor encontrar parámetros reproducibles y objetivos estandarizados que indiquen de forma consistente si la operación quirúrgica fue satisfactoria. Hemos diseñado un modelo de análisis 
mediante reconstrucción por ordenador que ayude a establecer una metodología objetiva a la hora de evaluar la eficacia de estos dos abordajes quirúrgicos: cirugía abierta o laparoscópica. Nuestro objetivo ha sido el determinar la cantidad de tejido extracapsular que rodea la próstata como marcador indirecto del control del cáncer y por lo tanto de que la cirugia resulte clínicamente satisfactoria.

Durante la última década, ha habido muchas investigaciones sobre la reconstrucción, visualización y análisis en $3 \mathrm{D}$ de datos médicos. ${ }^{2-9}$ Estas técnicas se usan rutinariamente en el examen científico de órganos como el corazón ${ }^{8}$ y el cerebro. ${ }^{9}$ Basset y cols. ${ }^{6}$ reconstruyeron próstatas usando un método de triangulación que aproxima la superficie entre dos cortes consecutivos, mediante una colección de parches triangulares planares consiguiendo un método que es rápido y satisface las representaciones de formas anatómicas como la próstata. Otros ${ }^{7}$ han reconstruido modelos de próstata en 3D a partir de la histopatología y nosotros hemos publicado nuestros esfuerzos en esta disciplina. ${ }^{10-12}$ No hay duda de que la visualización y el análisis científicos son metodologías que se siguen usando y se siguen ampliando al dominio de la medicina.

La metodología para definir y asegurar que un procedimiento quirúrgico es satisfactorio puede tener implicaciones importantes. En el campo de los ensayos clínicos, cuando se añade un tratamiento neoadyuvante o adyuvante a un procedimiento quirúrgico para estudiar si aporta beneficios, es fundamental que el procedimiento quirúrgico cumpla un estándar de uniformidad, para evitar que haya variables adicionales en el procedimiento que determinen las diferencias en los resultados. Por ejemplo, se ha investigado y documentado la importancia de un procedimiento quirúrgico estandarizado en el contexto de los ensayos clínicos que estudian los beneficios de la quimioterapia neoadyuvante antes de la cistectomía ${ }^{13}$. Aunque durante mucho tiempo, la prostatectomía retropúbica y la perineal han sido los estándares quirúrgicos, la prostatectomía radical laparoscópica y, más recientemente, la prostatectomía radical con ayuda robótica han puesto en cuestión este estándar. Son importantes los métodos para valorar inmediatamente la adecuación de la extirpación de la pieza mediante estos distintos abordajes.
Este estudio demuestra que, en nuestra experiencia, un parámetro objetivo indicativo de la idoneidad quirúrgica es el porcentaje de glándula prostática que esta cubierto por tejido fibroadiposo extracapsular; este porcentaje es mayor en el abordaje laparoscópico que en el retropúbico. El vértice de la pieza quirúrgica a menudo es un área de cobertura marginal de tejido extracapsular. La evaluación segmentaria de la glándula demuestra que, cuando se realizaba un procedimiento sin preservación de los nervios, se encuentra una cobertura significativamente mayor en los segmentos inferolaterales con el abordaje laparoscópico que con el abordaje abierto. De otra parte, cuando se realizaba un procedimiento de preservación de los nervios, se encuentra un porcentaje estadísticamente mayor de superficie capsular cubierta por tejido fibroadiposo extracapsular en el segmento apical, en los casos en que se usa el abordaje laparoscópico. Estos hallazgos respaldan el hecho de que la disección laparoscópica permite una mejor disección fuera de los límites capsulares e incorpora una mayor cantidad y cobertura de tejido extracapsular con la pieza. Los hallazgos de márgenes positivos en el grupo laparoscópico, que parecerían entrar en conflicto con la presencia de más tejido extracapsular con la laparoscopia, se explican por la localización de los márgenes; a saber, apical en 2 y asociado a pT3 en uno. Los primeros $5 \mathrm{~mm}$ del vértice de la próstata donde se identificaron estos márgenes no se incluyeron en el modelo de ordenador, sino que se remitieron como pieza por separado, por los motivos indicados en la sección de materiales y métodos. Por todo ello, los márgenes apicales son un reto para el cirujano laparoscópico como lo son en la cirugía abierta, debido a la ausencia de cápsula bien definida y la escasa cubierta de tejido extracapsular en esta región de la glándula.

En conclusión, la extirpación laparoscópica de la próstata en nuestra serie, en general, aportó una mayor cobertura de tejido extracapsular que el procedimiento abierto. Además, esta cobertura fue también mayor en las áreas inferolateral y apical en la disección sin preservación de nervios y en el área apical en la disección con preservación de nervios. La cuestión de si la prostatectomía laparoscopia con ayuda robótica puede igualar o mejorar estos resultados es tema de estudios futuros. 


\section{REFERENCIAS}

1. Guillonneau B, el-Fettouh H, Baumert H, Cathelineau X, Doublet JD, Fromont G et al. Laparoscopic radical prostatectomy: oncological evaluation after 1,000 cases a Montsouris Institute. J Urol. 2003;169(4):1261-1266.

2. Rabah DM, Schellhammer PF, Diaz JI, Tuerk I, Soderdahl DW, Fabrizio MD. Laparoscopic radical prostatectomy: is intact organ removal attainable? Study of margin status. J Endourol. 2004;18(8):731-734.

3. Soderdahl DW, Diaz JI, Rabah DM, Schellhammer PF, Fabrizio MD. Laparoscopic radical prostatectomy: evaluation of specimen pathologic features to critically assess and modify surgical technique. Urology. 2005; 66 (3):552-556.

4. Donohue RE, Miller GJ. Adenocarcinoma of the Prostate: Biopsy to Whole Mount. Denver VA experience. Urol Clin North Am. 1991;18(3):449-452.

5. Xuan J, Sesterhenn I, Hayes WS, Wang Y, Adali T., Yagi Y, Freedman MT and Mun SK. Surface Reconstruction and Visualization of the Surgical Prostate Model. Proceedings of the SPIE Medical Imaging Conference, 1997;3031:50-61.

6. Basset O, Dautraix Ricard I, Gimenez G,Mestas JL. ThreeDimensional Reconstruction of the Prostate from Transverse or Sagittal Ultrasonic Images. Proceedings of SPIE the International Society for Optical Engineering 1993; 1771:559-566.

7. Adiga PSU, Chaudhuri BB. Automatic Prostate Cancer Grading System based on 3D Histo-pathological Images. Proceedings of IAPR Workshop on Machine Vision Applications. Univ. Tokyo. 1998, pp.250-3. Tokyo, Japan.

8. Fitton I, Shen J, Perron J-M, Kerouani A, Roudaut R, Barat J-L.Regional Myocardial Wall Thickening of the Left Ventricle from Segmentation of Echocardiographic Images. SPIE-Int. Soc. Opt. Eng. Proceedings of Spie - the International Society for Optical Engineering 2001;4549:58-63.
9. Xu C, Pham DLP, Etemad ME, Yu DN, Prince JL. Reconstruction of the Central Layer of the Human Cerebral Cortex from MR Images in Proc. of the First International Conference on Medical Image Computing and Computer Assisted Interventions (MICCAI'98) 1998:482-488.

10. Rania H, McKenzie FD, Schellhammer P, Diaz JI. Quantitation of Extra-Capsular Prostate Tissue from Reconstructed Tissue Images. In Proceedings of the Forth IEEE Symposium on BioInformatics and BioEngineering (IEEE BIBE 2004) 2004:191-196.

11. McKenzie FD, Diaz JI, Schellhammer P, Rania H. Towards Statistical Inferences of Successful Prostate Surgery. In Proceedings of the 25th Annual International Conference of the IEEE Engineering in Medicine and Biology Society (IEEE EMBS 2003) 2003:572-575.

12. McKenzie FD, Rania H, Jennifer Seevinck, Schellhammer P, Diaz JI. Prostate Gland and Extra-Capsular Tissue 3D Reconstruction and Measurement. In Proceedings of the Third IEEE Symposium on BioInformatics and BioEngineering (IEEE BIBE 2003) 2003: 246-250.

13. Herr HW, Faulkner JR, Grossman HB, Natale RB, deVere White R, Sarosdy MF et al. Surgical Factors Influence Bladder Cancer Outcomes: A Cooperative Group Report. J Clin Oncol. 2004; 22(14): 2781-2789.

Correspondencia autor: Dr. J.I. Diaz

Director of Pathology and Molecular Oncology

Targeted Therapy Program. Cancer Therapy Research Center. Institute for Drug Development

San Antonio Cancer Institute, University of Texas Health

Science Center-San Antonio

14960 Omicron Drive San Antonio

Tel.: 78245-3217

E-mail autor: jdiaz@idd.org

Información artículo: Original - Próstata 